\title{
Strengthening Mechanism in Ultra Low Carbon Martensitic Steel
}

\author{
Setsuo TAKAKI, Kinh-Luan NGO-HUYNH, Nobuo NAKADA and Toshihiro TSUCHIYAMA \\ Department of Materials Science and Engineering, Kyushu University 744 Motooka, Nishi-ku, Fukuoka, 819-0395 Japan. E-mail: \\ takaki@zaiko.kyushu-u.ac.jp
}

(Received on October 19, 2011; accepted on November 14, 2011)

\begin{abstract}
In this paper, the strengthening mechanism of martensite was investigated by using an ultra low carbon $\mathrm{Fe}-18 \% \mathrm{Ni}$ alloy to eliminate the confusion caused by carbon. In addition, $\mathrm{Fe}-18 \% \mathrm{Ni}-\mathrm{C}$ alloys were used to compare with the data of $\mathrm{Fe}-\mathrm{C}$ alloys already reported and the effect of solute $\mathrm{Ni}$ was discussed in terms of solid solution strengthening in martensitic steels. The results obtained are as follows: 1) Microstructure of lath martensite is markedly refined by lowering the solution treatment temperature, nevertheless no large difference is found on the nominal stress-strain curves, especially on the yielding behavior. 2) Low elastic limit of ultra low carbon martensite is due to the existence of high density of mobile dislocation which has been introduced during martensitic transformation. Extra mobile dislocations can be eliminated by charging small amount of pre-strain more than $0.6 \%$ and this leads to an increase of $0.2 \%$ proof stress. 3) Substantial yield strength of carbon free martensite is determined by only the mechanism of dislocation strengthening without the contribution by grain refinement strengthening depending on microstructural parameters such as prior austenite grain size, packet size and block size. 4) Solid solution strengthening by $\mathrm{Ni}$ does not appear in martensitic steels which contains high density of dislocation, even though it is significant in ferritic steels.
\end{abstract}

KEY WORDS: lath martensite; elastic limit; yield strength; strengthening mechanism; Bailey-Hirsch relation; dislocation density; mobile dislocation; dislocation reaction.

\section{Introduction}

Martensite is a basic structure used for high strength steels and it is well known that carbon gives a large influence to the strength of martensite. ${ }^{1-5)}$ Martensitic transformation is convenient to obtain super-saturated solid solution for carbon but it also results in the formation of complicated microstructure, so-called lath martensitic structure composed of packets, blocks and laths. With increasing carbon content, lath martensitic structure tends to be refined. ${ }^{6}$ ) In the case of low carbon martensite, it has been pointed out that the size of packet $^{7)}$ or block ${ }^{8)}$ is an important parameter in the discussion of the structure-strength relationship of lath martensite. Besides, a large amount of dislocation is introduced during martensitic transformation and it also contributes to the strengthening of martensitic steels through the mechanism of dislocation strengthening. Dislocation density is also enhanced with increasing carbon content; $5 \times 10^{14} / \mathrm{m}^{2}$ for $\mathrm{Fe}-0.01 \% \mathrm{C}$ alloy and $1.5 \times 10^{15} / \mathrm{m}^{2}$ for $\mathrm{Fe}-$ $0.1 \% \mathrm{C}$ alloy. ${ }^{9)}$ Such various contributions by carbon sometimes cause confusion for understanding of strengthening mechanism in martensitic steels. So far, it is generally accepted that all of strengthening factors; grain refinement strengthening depending on microstructure, dislocation strengthening, solid solution strengthening by carbon and the effect of strain aging by carbon can contribute to the strength of matrensitic steels. ${ }^{10)}$

On the other hand, it is generally known that martensitic steels are characterized by their low elastic limit and low
$0.2 \%$ proof stress. Dislocation plays a role to increase the strength of steel on one side but it may produce plastic strain through their movement on the other side. Author et al. recently reported for ultra low carbon $\mathrm{Fe}-18 \% \mathrm{Ni}$ alloy with typical lath martensitic structure that about a half of dislocations disappear on the way of increasing applied stress and this leads to the production of fairly large plastic strain. ${ }^{11)}$ This result suggests that $0.2 \%$ proof stress of martensite can be easily changed by charging a very small amount of pre-strain. In the other words, "substantial yield strength" of martensite should be evaluated after eliminating such extra mobile dislocations.

As mentioned above, carbon gives many influences on the strengthening mechanism of martensitic steels. In this paper, therefore, the strengthening mechanism of martensite was investigated by using an ultra low carbon $\mathrm{Fe}-18 \% \mathrm{Ni}$ alloy to eliminate the confusion caused by carbon. In addition, $\mathrm{Fe}-18 \% \mathrm{Ni}-\mathrm{C}$ alloys were used to compare with the data of $\mathrm{Fe}-\mathrm{C}$ alloys already reported and the effect of solute $\mathrm{Ni}$ was discussed in terms of solid solution strengthening in martensitic steels.

\section{Experimental Procedure}

Chemical compositions of the materials used in this investigation are shown in Table 1. Mainly used material is $\mathrm{Fe}-18 \% \mathrm{Ni}-0.001 \% \mathrm{C}$ alloy in which carbon and nitrogen are reduced to $30 \mathrm{ppm}$ in total. Since the effect of nitrogen cannot be neglected on the strength of martensite, the carbon 
Table 1. Chemical composition of the materials used (mass \%).

\begin{tabular}{cccccccccc}
\hline & $\mathrm{C}$ & $\mathrm{N}$ & $\mathrm{Si}$ & $\mathrm{Mn}$ & $\mathrm{P}$ & $\mathrm{S}$ & $\mathrm{Ni}$ & $\mathrm{Fe}$ & $\mathrm{C}_{\mathrm{eq}}{ }^{*}$ \\
\hline Commercial pure iron & 0.001 & 0.0016 & $<0.01$ & $<0.01$ & $<0.001$ & $<0.0002$ & - & bal. & - \\
$\mathrm{Fe}-18 \% \mathrm{Ni}-0.001 \% \mathrm{C}$ & 0.001 & 0.002 & $<0.01$ & $<0.001$ & 0.006 & $<0.0002$ & 17.83 & bal. & 0.0018 \\
$\mathrm{Fe}-18 \% \mathrm{Ni}-0.002 \% \mathrm{C}$ & 0.002 & $<0.001$ & $<0.001$ & 0.001 & 0.006 & $<0.0002$ & 18.14 & bal. & 0.0024 \\
$\mathrm{Fe}-18 \% \mathrm{Ni}-0.009 \% \mathrm{C}$ & 0.009 & 0.0019 & $<0.001$ & $<0.001$ & $<0.001$ & $<0.0002$ & 18.15 & bal. & 0.0098 \\
$\mathrm{Fe}-18 \% \mathrm{Ni}-0.042 \% \mathrm{C}$ & 0.042 & $<0.001$ & $<0.001$ & 0.002 & $<0.001$ & 0.0002 & 18.02 & bal. & 0.0424 \\
$\mathrm{Fe}-18 \% \mathrm{Ni}-0.140 \% \mathrm{C}$ & 0.14 & $<0.001$ & $<0.001$ & $<0.001$ & $<0.001$ & $<0.0002$ & 18.21 & bal. & 0.1404 \\
\hline
\end{tabular}

* $\mathrm{C}_{\mathrm{eq}}=\mathrm{C}+0.4 \mathrm{~N}, \mathrm{~N}<0.001$ was treated as $\mathrm{N}=0.001$.

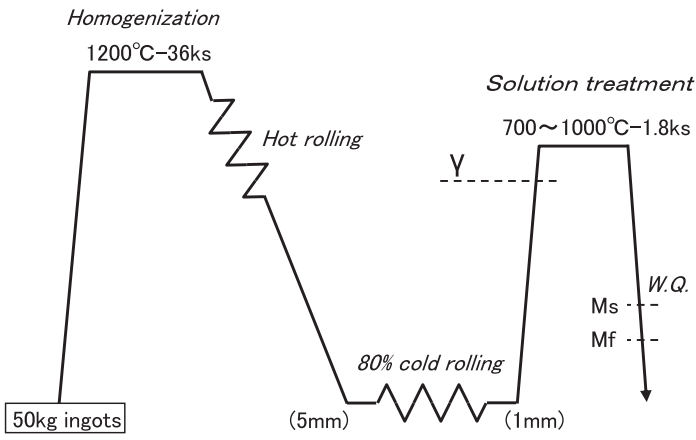

Fig. 1. Treatment route for $\mathrm{Fe}-18 \% \mathrm{Ni}$ series alloys.

equivalent $\mathrm{C}_{\mathrm{eq}}(=\mathrm{C}+0.4 \mathrm{~N})^{12)}$ was used for the evaluation of strength in martensitic steels. The materials were prepared by vacuum induction melting followed by casting into metallic mold. The ingots $(50 \mathrm{~kg})$ were homogenized at $1200^{\circ} \mathrm{C}$ for $36 \mathrm{ks}$ and then hot rolled to steel plates. Treatment route after the homogenization is displayed in Fig. 1 for $\mathrm{Fe}-18 \% \mathrm{Ni}$ series alloys. Hot rolled steel plates with the thickness $5 \mathrm{~mm}$ were cold rolled by $80 \%$ reduction in thickness and then subjected to the solution treatment of $900^{\circ} \mathrm{C}-1.8 \mathrm{ks}$ followed by water quenching. For $\mathrm{Fe}-$ $18 \% \mathrm{Ni}-0.001 \% \mathrm{C}$ alloy, solution treatment temperature was varied in the temperature range of $700-1000^{\circ} \mathrm{C}$ to investigate the effect of austenite grain size on microstructure and mechanical property of ultra low carbon martensite. It was confirmed by the measurement of saturation magnetization that fully martensitic structure is obtained in all of $\mathrm{Fe}-$ $18 \% \mathrm{Ni}$ series alloys. Commercial pure iron was used to investigate the relation between dislocation density and yield strength in cold rolled iron. After the homogenizing annealing, the ingot was hot rolled to several steel plates with various thickness in the range of $1-10 \mathrm{~mm}$ and then subjected to the annealing of $800^{\circ} \mathrm{C}-1.8 \mathrm{ks}$ followed by water quenching. Ferrite grain size of the obtained steel plates was 100 $120 \mu \mathrm{m}$. These steel plates were cold rolled to $1 \mathrm{~mm}$ in thickness to introduce dislocation into iron in different dislocation density.

Microstructure of specimens was observed with transmission electron microscope (TEM) and scanning electron microscope with electron back scattering diffraction system (EBSD-SEM). Dislocation density was measured on the sheet samples of $1 \mathrm{~mm}$ thick by the method of X-ray diffraction analysis. ${ }^{13)}$ The surface of samples applied to X-ray analysis was flattened by sand paper grinding and then electrolytically polished by $0.1 \mathrm{~mm}$ to eliminate the surface layer affected by sand paper grinding. Dislocation density of cold rolled iron was evaluated by the mean value of three times measurement. Hardness was evaluated by the mean value of seven times measurements on Vickers hardness $(98 \mathrm{~N})$. Tensile tests were performed with Instron type testing machine $(49 \mathrm{kN})$ at the cross head speed of $1 \mathrm{~mm} / \mathrm{s}$ on the test piece JIS13-B with the gauge dimension of $50 \mathrm{~mm}$ length and $12.5 \mathrm{~mm}$ width.

\section{Experimental Results}

\subsection{Effect of Microstructure on Yielding Behavior of Ultra Low Carbon Martensitie}

According to the phase diagram of Fe-Ni binary alloy, it was expected that $\mathrm{Fe}-18 \% \mathrm{Ni}$ alloy has austenite single phase above $600^{\circ} \mathrm{C}$. Figure 2 displays the effect of solution treatment temperature on the microstructure obtained with EBSD-SEM. The Ms temperature was same at around $290^{\circ} \mathrm{C}$ independent of solution treatment temperature. With lowering the solution treatment temperature, austenite grain size becomes smaller and the microstructure such as packet and block is refined with reduced austenite grain size. Although all specimens have lath martensitic structure, very large difference is found in the microstructure depending on the solution treatment temperature. On the other hand, Fig. 3 shows nominal stress-strain curves of the specimens having the microstructure shown in Fig. 2. It should be noted that no large difference is found in their nominal stressstrain curves despite having completely different microstructure. These results demonstrate that the microstructural factors such as prior austenite grain size, packet size and block size do not affect the yielding behavior and ultimate tensile strength of ultra low carbon martensite.

\subsection{Effect of Mobile Dislocation on Yielding Behavior of Ultra Low Carbon Martensitie}

In Fig. 3, yielding behavior of each specimen is characterized by very low elastic limit less than $0.3 \mathrm{GPa}$. It has been already indicated that extra mobile dislocations relate to the low elastic limit of ultra low carbon martensitic steel. ${ }^{11)}$ Figure 4 shows the change of dislocation density during tensile deformation. Dislocation density was measured at the gauge portion of a tensile test piece after loading to the selected stress (a). Tensile plastic strain was obtained by subtracting elastic strain from the measured total strain (b). The original dislocation density $\rho_{0}$ is high as $7 \times 10^{15} / \mathrm{m}^{2}$ in as-quenched specimen but decreases to around a half of $\rho_{0}$ in the early deformation stage below $0.6 \%$ plastic strain. 

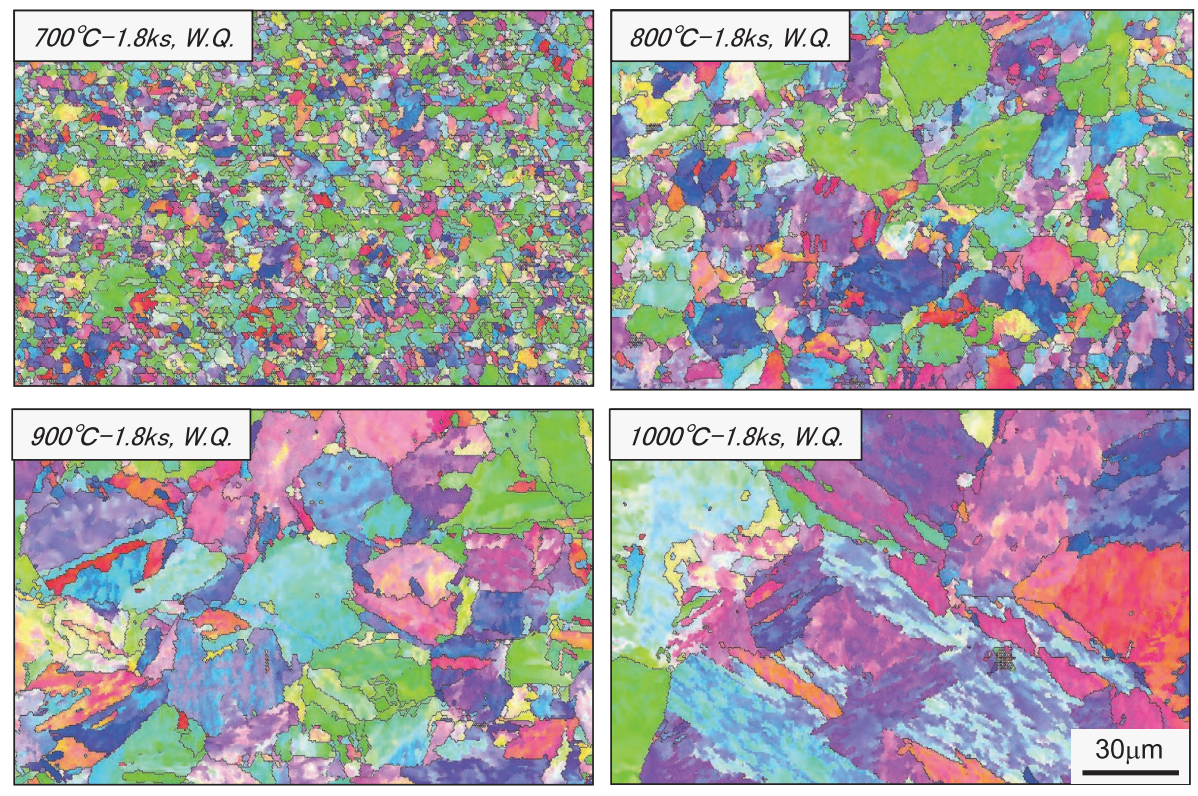

Fig. 2. Effect of solution treatment temperature on the microstructure of $\mathrm{Fe}-18 \% \mathrm{Ni}-0.001 \% \mathrm{C}$ alloy with lath martensitic structure. Observed from the transverse direction against rolling direction.

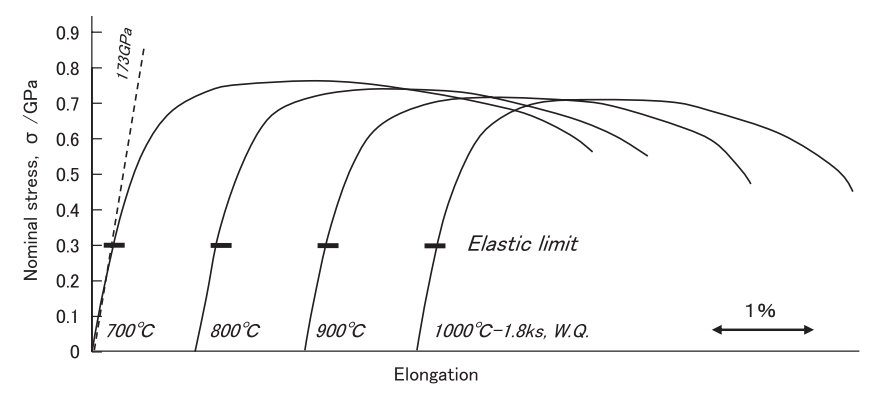

Fig. 3. Stress strain curves of $\mathrm{Fe}-18 \% \mathrm{Ni}-0.001 \% \mathrm{C}$ alloy with different microstructures as shown in Fig. 2. Young's modulus $(173 \mathrm{GPa})$ was measured by the quartz oscillation method.

This means that a half of dislocations have disappeared through dislocation reaction during increasing applied stress. The plastic strain $\varepsilon$ produced by dislocation movement can be estimated by $\varepsilon=\rho_{\mathrm{m}} \mathrm{bx} / 2$, where $\rho_{\mathrm{m}}$, b and $\mathrm{x}$ are the total length of moving dislocations in unit volume, Burgers vector $(0.25 \mathrm{~nm})$ and the mean movement distance of dislocations. Mean dislocation spacing $\mathrm{L}$ is roughly estimated at about $20 \mathrm{~nm}$ from $\mathrm{L}=\left(3 / \rho_{0}\right)^{1 / 2}$ for $\rho_{0}=7 \times 10^{15} / \mathrm{m}^{2}$ so that dislocations have to move by $10 \mathrm{~nm}$ at least to meet each other. Under the presumption $\rho_{\mathrm{m}}=\rho_{0}$, the plastic strain produced by dislocation movement is expected at $\varepsilon=0.00875$. This estimation indicates that about $1 \%$ of plastic strain can be produced by very small movement of dislocations in martensitic steels. In addition, it is probable that a part of dislocations have disappeared through dislocation reaction during the movement. After eliminating extra mobile dislocations, dislocation density becomes constant at around $3.5 \times 10^{15} / \mathrm{m}^{2}$ and also flow stress levels off at about $0.7 \mathrm{GPa}$. Thus, it can be concluded that the low $0.2 \%$ proof stress of martensitic steels is owing to the high density of mobile dislocation and that substantial yield strength of martensite should be evaluated after eliminating extra mobile dislocations. In the case of pre-straining by cold rolling, it was found that skin pass rolling by $5 \%$ thickness

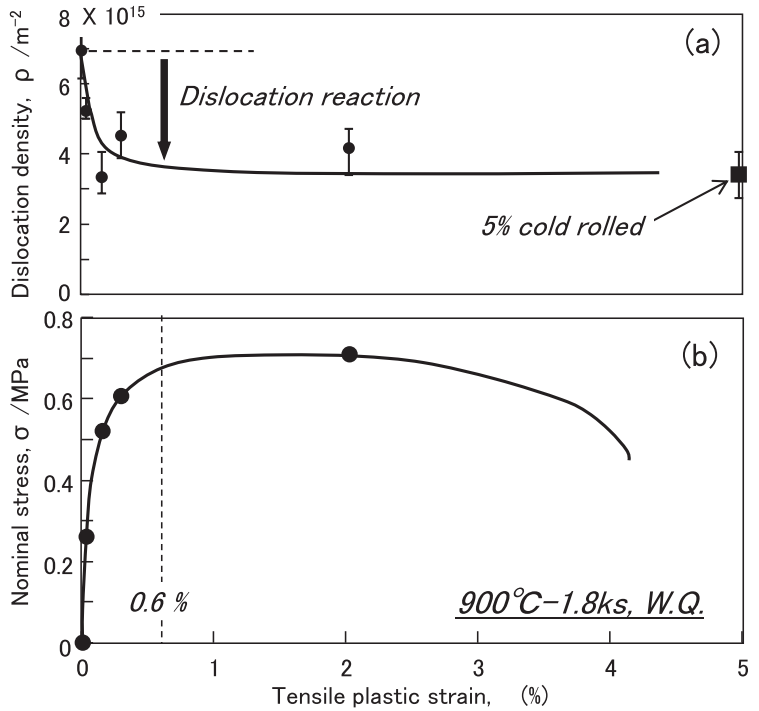

Fig. 4. Changes in dislocation density (a) and applied stress (b) as a function of tensile plastic strain in as-quenched $\mathrm{Fe}-$ $18 \% \mathrm{Ni}-0.001 \% \mathrm{C}$ alloy with lath martensitic structure.

reduction is enough to eliminate extra mobile dislocations.

Figure 5 shows TEM microstructure of as-quenched specimen (a) and $2 \%$ tensile deformed specimen (b). No large difference was found in low magnified TEM images but it looks that the distribution of intralath dislocations is slightly changed after the deformation: Dislocation disperses randomly in the as-quenched specimen (a) but tangle each other to form network cell structure in the deformed specimen (b). The same behavior has also been reported in a martensitic steel containing $0.2 \% \mathrm{C}^{7}$ ) This means that mobile dislocations change the arrangement from unstable to stable distribution by charging small amount of deformation.

Figure 6 illustrates the change of dislocation arrangement during deformation. In as-quenched martensite, the dislocations introduced by martensitic transformation should be 

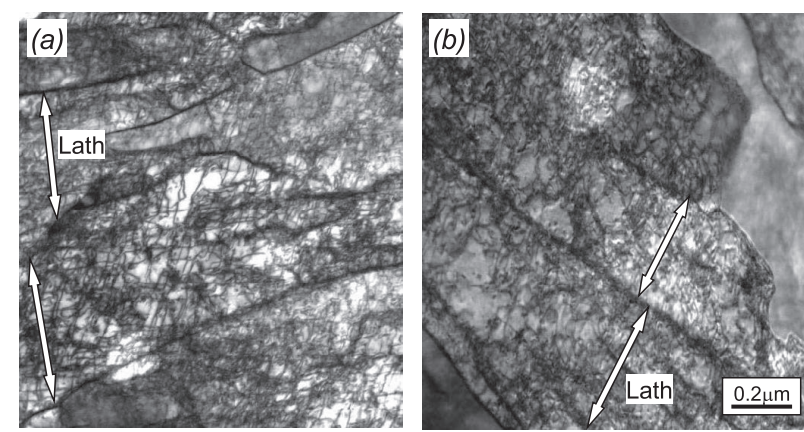

Fig. 5. TEM microstructure of $\mathrm{Fe}-18 \% \mathrm{Ni}-0.001 \% \mathrm{C}$ alloy asquenched (a) and tensile deformed by $2 \%$ (b).

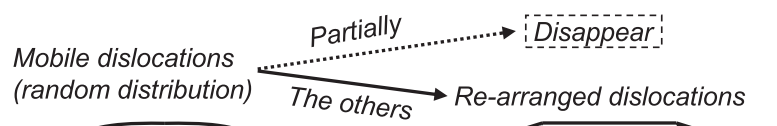

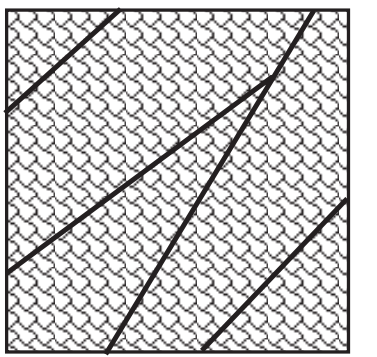

As-quenched martensite

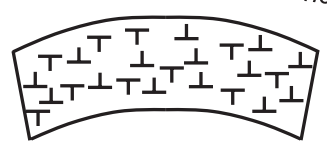

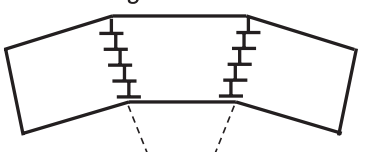

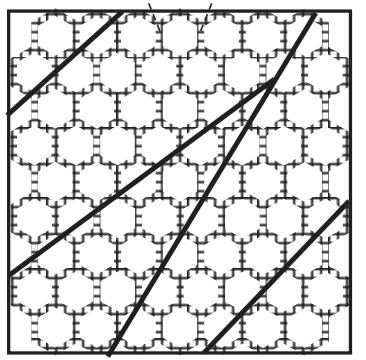

$5 \%$ cold rolled martensite
Fig. 6. Schematic illustration showing the change of dislocation distribution by small amount of deformation in lath martensitic steel.

substantially mobile dislocation which distribute randomly in matrix. During increasing applied stress, mobile dislocations move slightly and a part of dislocations disappear through dislocation reaction. On the other hand, the other remained dislocations move to stable sites to reduce the elastic strain energy each other and form tangled network cell structure. Since the retained dislocations produce a high flow stress $(0.72 \mathrm{GPa})$ as shown in Fig. 4, the tangling of dislocations seems to be essential to produce a high yield stress. Therefore, from a view point of dislocation strengthening, the density of tangled dislocations can be called as "effective dislocation density" as contrasted with the total dislocation density including extra mobile dislocations.

\subsection{Estimation of Substantial Yield Strength in Ultra Low Carbon Martensitie}

Figure 7 represents the effect of skin pass rolling (5\% in thickness reduction) on the yielding behavior. Skin pass rolling does not affect the ultimate tensile strength so much but both of elastic limit and $0.2 \%$ proof stress are markedly increased. This result demonstrates the fact that extra mobile dislocations produce a plastic strain during loading and lower $0.2 \%$ proof stress in as-quenched martensite. Figure 8 shows the changes of dislocation density (a) and $0.2 \%$ proof stress (b) with skin pass rolling. The dislocation density of as-quenched specimens is very high but slightly different

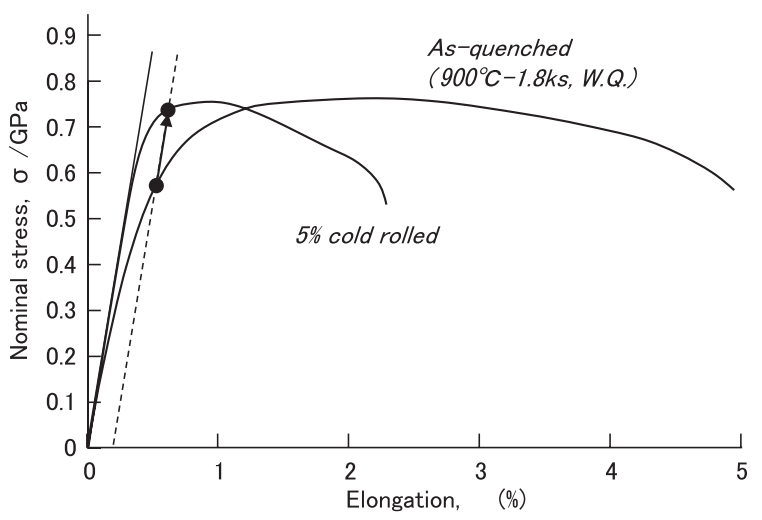

Fig. 7. Effect of skin pass rolling on the yielding behavior of $\mathrm{Fe}-$ $18 \% \mathrm{Ni}-0.001 \% \mathrm{C}$ alloy with lath martensitic structure.

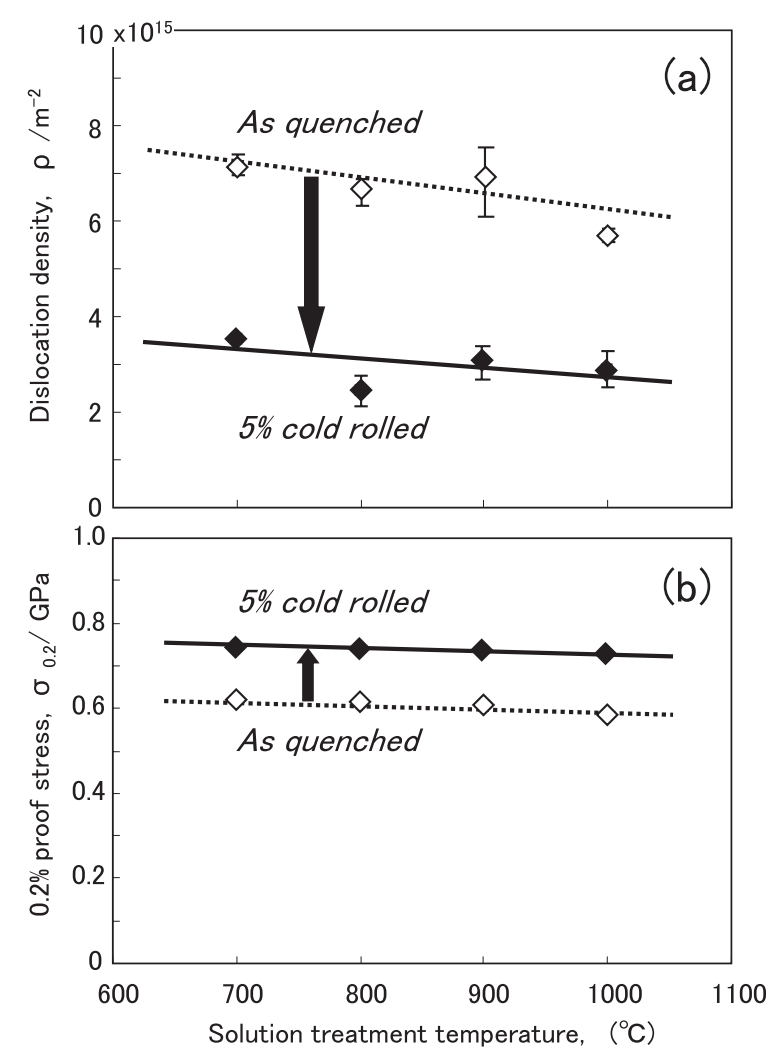

Fig. 8. Changes in dislocation density (a) and $0.2 \%$ proof stress (b) by $5 \%$ cold rolling in $\mathrm{Fe}-18 \% \mathrm{Ni}-0.001 \% \mathrm{C}$ alloy with lath martensitic structure.

depending on the solution treatment conditions in the range of $5-7 \times 10^{15} / \mathrm{m}^{2}$. It seems that the dislocation density increases with reducing austenite grain size. Since the Ms temperature was almost same in every specimen, it is probable that the dislocation introduction is kinetically promoted during martensitic transformation by reducing austenite grain size. After skin pass rolling, the dislocation density decreases to the level of $3 \times 10^{15} / \mathrm{m}^{2}$. This means that about a half of dislocations disappear during skin pass rolling. On the other hand, $0.2 \%$ proof stress is in the range of $0.5-0.6 \mathrm{GPa}$ for asquenched specimens but it can be enhanced by about $0.2 \mathrm{GPa}$ after skin pass rolling. Even after skin pass rolling, $0.2 \%$ proof stress is slightly higher in the specimen with finer microtructure but it is not due to the contribution by microstructure but due to small difference in effective dislocation 
density as discussed below.

\section{Discussion}

\subsection{Estimation of Dislocation Strengthening in Ultra Low Carbon Martensite}

Figure 9 shows the relation between dislocation density; $\rho$ and $0.2 \%$ proof stress; $\sigma_{0.2}$ in cold rolled iron. The following relationship was established for cold rolled iron.

$$
\sigma_{0.2}[\mathrm{GPa}]=0.1+1.2 \times 10^{-8} \rho^{1 / 2}
$$

In the case of cold rolling, the maximum dislocation density achieved is around $10^{15} / \mathrm{m}^{2}$ and $0.2 \%$ proof stress increases to about $0.6 \mathrm{GPa}$. On the other hand, very high dislocation density above $5 \times 10^{15} / \mathrm{m}^{2}$ can be realized in the specimens with martensitic structure. It is interesting that $0.2 \%$ proof stress of as-quenched martenite is fairly low despite of its high dislocation density, as plotted in the figure. The reason is due to the existence of mobile dislocation as mentioned above. Here, it should be noted that the plots as to the specimens with skin pass rolling are just on the extended line of the Bailey Hirsch relation that was established for cold rolled iron. This result indicates that substantial yield strength of ultra low carbon martensite can be explained only by the "effective dislocation density" on the basis of dislocation strengthening mechanism. If there were some additional contributions by microstructure, the data of specimens with skin pass rolling should shift toward upper side from the extended Bailey-Hirsch line.

However, in the case of martensite containing $0.2 \% \mathrm{C}$, the increment of $0.2 \%$ proof stress has been reasonably explained as a function of microstructural parameters such as packet size ${ }^{7)}$ or block size. ${ }^{8)}$ Besides, T. Swarr and G. Krauss have indicated that the packet size dependence of yield strength is significantly diminished in carbon free $\mathrm{Fe}-\mathrm{Mn}$ martensite. ${ }^{7)}$ It is probable that the yield strength of carbon free martensite does not depend on the microstructural parameters. Here, a question is why the yield strength of low carbon steels depends on the microstructural parameters. Unfortunately, there is no discussion from the view point of dislocation density in their original papers ${ }^{7,8}$ but there is a possibility that dislocation density has been also enhanced

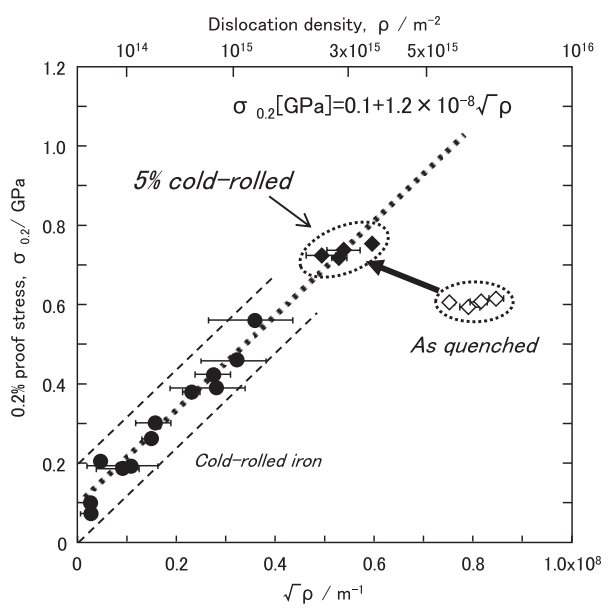

Fig. 9. Relation between dislocation density and $0.2 \%$ proof stress in cold rolled iron and $\mathrm{Fe}-18 \% \mathrm{Ni}-0.001 \% \mathrm{C}$ alloy with lath martensitic structure. by the refinement of microstructure. Another important point to be discussed is what represents the substantial yield strength of martensite. As mentioned above, $0.2 \%$ proof stress is determined by the movement of mobile dislocation, so that $0.2 \%$ proof stress might not reflect the substantial yield strength of martensite. The result of Fig. 4 suggests that $0.6 \%$ proof stress is reasonable for the evaluation of yield strength in as-quenched martensite. Anyway, on the yielding mechanism of low carbon martensite, further detailed investigations will be required from the overall view point taking every strengthening mechanism into consideration.

\subsection{Influence of Solid Solution Strengthening by $\mathrm{Ni}$ in Martensitic Steels}

In pure iron, it is difficult to obtain martensite experimentally because the Ms temperature is so high that ferritic transformation cannot be suppressed even by water quenching. However, the strength of imaginary pure iron martensite might be estimated from the relation between carbon content and strength in as-quenched low carbon martensitic steels. G. R. Speich has examined the carbon content dependence of strength of $\mathrm{Fe}-\mathrm{C}$ system martensitic steels in the carbon composition range below $0.2 \%{ }^{4}{ }^{4}$ Figure 10 displays the relation between carbon content and Vickers hardness of martensitie. Fitting curve can be expressed by the following equation.

$$
\mathrm{HV}[\mathrm{GPa}]=2.21+8 \times\left(\operatorname{mass} \% C_{e q}\right)^{2 / 3}
$$

Fitting by the function of $\left(\operatorname{mass} \% C_{e q}\right)$ or $\left(\operatorname{mass} \% C_{e q}\right)^{1 / 2}$ was tried and it was found that the fitting by $\left(\operatorname{mass} \% C_{e q}\right)^{2 / 3}$ is best in the carbon composition range below $0.2 \%$ at least. When a wider carbon composition range is applied for the discussion, the other fitting may be reasonable. Here, the fitting was performed not for discussing the effect of carbon on the strength of martensite but for estimating only the strength of imaginary pure iron martensite. Therefore, the fitting was performed in the narrow carbon composition range below $0.2 \%$ intentionally. It is interesting that both data for $\mathrm{Fe}-18 \% \mathrm{Ni}-\mathrm{C}$ and $\mathrm{Fe}-\mathrm{C}$ series alloys are just on the same line, although Ms temperature is low by about $200^{\circ} \mathrm{C}$ in $\mathrm{Fe}-18 \% \mathrm{Ni}-\mathrm{C}$ series alloys. With lowering Ms temperature, dislocation density of as quenched martensite must increase but, as can be seen, the difference in Ms temperature does not appear on the hardness of martensite. This sug-

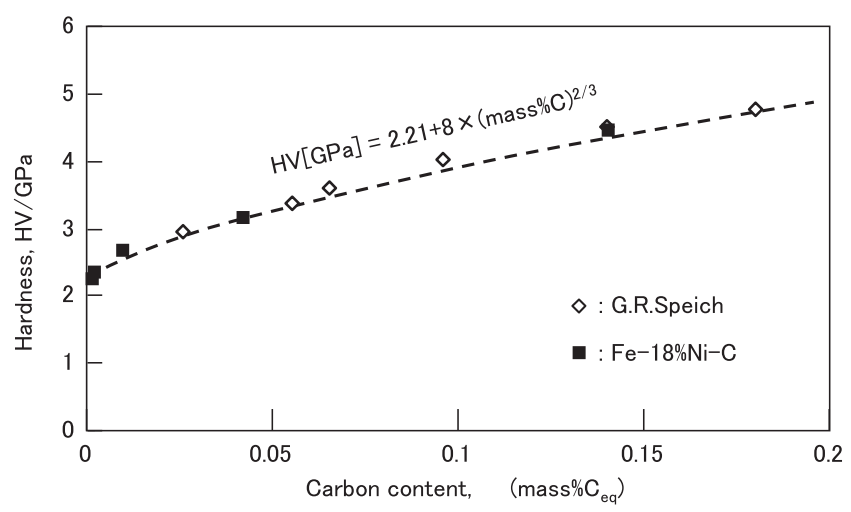

Fig. 10. Effect of carbon content on hardness of $\mathrm{Fe}-\mathrm{C}$ and $\mathrm{Fe}-$ $18 \% \mathrm{Ni}-\mathrm{C}$ system alloys with lath martensitic structure. 
gests that rearrangement of mobile dislocations takes place during Vickers hardness testing and the final dislocation arrangement reaches almost same situation independent of the initial dislocation density.

Figure 11 shows the change of $0.2 \%$ proof stress and ultimate tensile strength as a function of $\left(\operatorname{mass} \% C_{e q}\right)^{2 / 3}$. A clear linearity is found in both mechanical properties and the following equations were obtained:

$$
\begin{aligned}
& \sigma_{0.2}[\mathrm{GPa}]=0.56+1.75 \times\left(\operatorname{mass} \% C_{e q}\right)^{2 / 3} \\
& \sigma_{B}[\mathrm{GPa}]=0.71+2.56 \times\left(\operatorname{mass} \% C_{e q}\right)^{2 / 3}
\end{aligned}
$$

From these results, $0.2 \%$ proof stress and ultimate tensile strength of imaginary pure iron martensite are expected at $0.56 \mathrm{GPa}$ and $0.71 \mathrm{GPa}$, respectively. Here, it is found for $0.2 \%$ proof stress that both data of $\mathrm{Fe}-18 \% \mathrm{Ni}-\mathrm{C}$ and $\mathrm{Fe}-\mathrm{C}$ system alloys are also on the same line. This indicates that $18 \% \mathrm{Ni}$ addition does not give any influence even on the yielding behavior of martensitic steel.

With respect to the effect of solid solution strengthening by $\mathrm{Ni}$, it is well known that $\mathrm{Ni}$ is one of elements which produce fairly large solid solution strengthening in ferritic iron. For example, Fig. 12 shows the results reported by many researchers. ${ }^{14-16)}$ It is confirmed again that $\mathrm{Ni}$ gives large

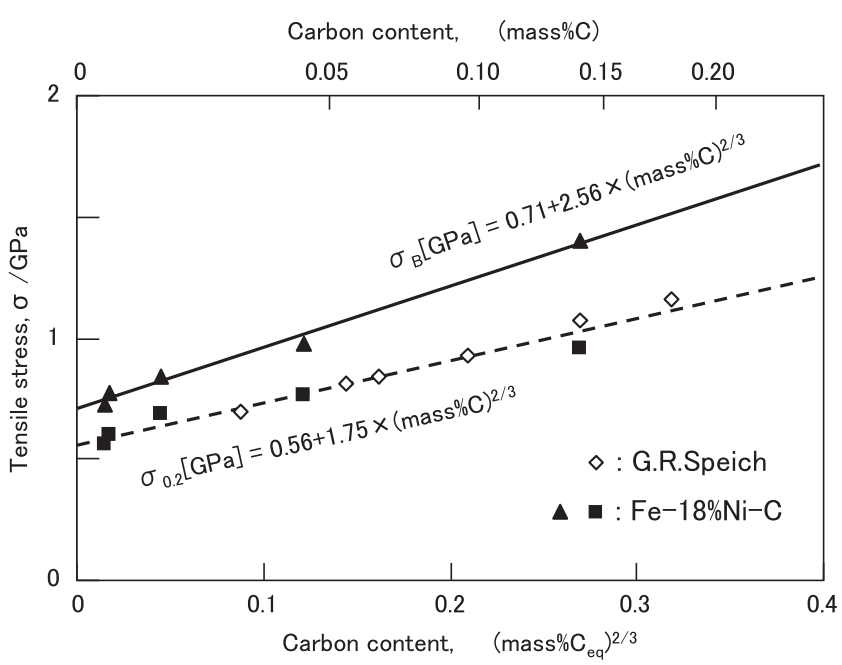

Fig. 11. Effect of carbon content on $0.2 \%$ proof stress $\left(\sigma_{0.2}\right)$ and ultimate tensile strength $\left(\sigma_{\mathrm{B}}\right)$ of $\mathrm{Fe}-\mathrm{C}$ and $\mathrm{Fe}-18 \% \mathrm{Ni}-\mathrm{C}$ system alloys with lath martensitic structure.

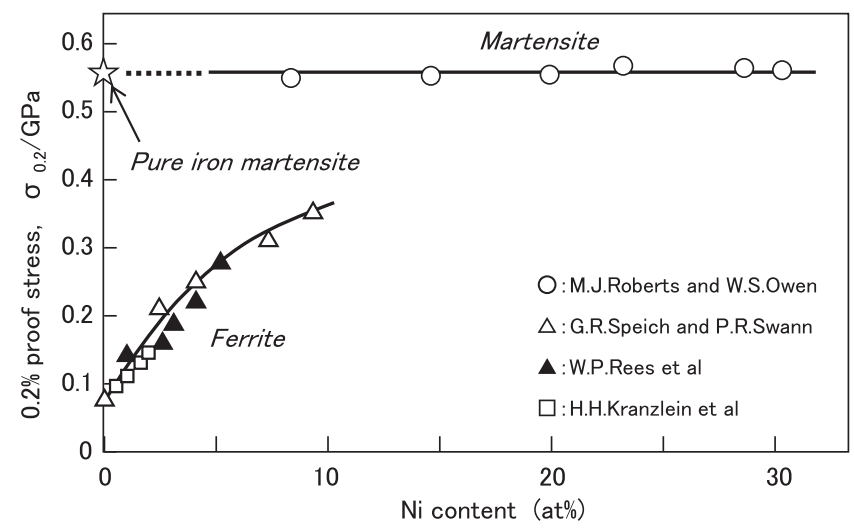

Fig. 12. Effect of $\mathrm{Ni}$ content on $0.2 \%$ proof stress in Fe-Ni binary alloys with lath martensitic or ferritic structure. effect on the yield strength of ferritic steel. On the other hand, the data for martensite has been reported in $\mathrm{Fe}-(8-$ $30) \% \mathrm{Ni}$ alloys by M. J. Roberts and W. S. Owen. ${ }^{17)}$ They pointed out that $0.2 \%$ proof stress of martensite is constant regardless of $\mathrm{Ni}$ content in the composition range above $8 \%$. As for the Ni content region below $8 \%$, some effect by $\mathrm{Ni}$ addition has been suggested in their original paper. However, it is found that the $0.2 \%$ proof stress of imaginary pure iron martensite $(0.56 \mathrm{GPa})$ is just same as those in $\mathrm{Fe}-\mathrm{Ni}$ alloys. This result demonstrates again that $\mathrm{Ni}$ does not give any influence on the strength of martensite. In the other words, this means that the effect of solid solution strengthening by Ni disappears in martensitic steels. Same phenomenon has been found in $\mathrm{Cu}$ bearing martensitic steels: Effect of solid solution strengthening by $\mathrm{Cu}$ does not appear in the specimens with martensitic structure. ${ }^{18)}$ Such a phenomenon will be explained by considering the interaction between elastic strain caused by dislocation and lattice strain of a solute atom. Solid solution strengthening is produced by the interaction between the elastic stress fields formed by solute atom and dislocation. In the case of substitutional elements like $\mathrm{Ni}$ and $\mathrm{Cu}$, the interaction with dislocation is not so large because the elastic strain produced by solid solution is very small in comparison with interstitial elements such as $\mathrm{C}$ and $\mathrm{N}$. For example, atomic diameter of $\mathrm{Fe}, \mathrm{Ni}$ and $\mathrm{C}$ is $0.248 \mathrm{~nm}^{19)} 0.258 \mathrm{~nm}^{19)}$ and $0.154 \mathrm{~nm}^{20)}$ at room temperature, respectively. $\mathrm{Ni}$ is replaced with $\mathrm{Fe}$ in bcc lattice but $\mathrm{C}$ locates at the octahedral space interstitially. The displacement caused by solid solution is very small as $0.01 \mathrm{~nm}$ for $\mathrm{Ni}$ but very large as $0.116 \mathrm{~nm}$ for $\mathrm{C}$. This suggests that $\mathrm{C}$ produces about 10 times larger lattice strain in comparison with Ni. By the way, the dislocation spacing in martensite is so small (about $20 \mathrm{~nm}$ ), as estimated above, that the stress field of dislocations should overlap each other. Under such a severe stress condition, the small stress field of substitutionally solute atoms might be drowned by the overlapped stress field of dislocations, while the large stress field of interstitially solute atoms might produce some interaction against dislocation. In addition, it is likely that Cottrell locking by interstitial atoms works effectively to increase the interaction against dislocation. This is the reason why the effect of $\mathrm{C}$ and $\mathrm{N}$ appears and the effect of substitutional elements disappears in steels with martensitic structure. As a result, in carbon free martensite, substantial yield strength can be evaluated by adding the contribution of dislocation strengthening to the friction stress of pure iron (about $0.1 \mathrm{GPa}$ ), as expected from the result of Fig. 9.

\section{Conclusion}

In an ultra low carbon $\mathrm{Fe}-18 \% \mathrm{Ni}$ alloy with lath martensitic structure, strengthening mechanism was investigated in terms of microstructure, dislocation density and solid solution strengthening by $\mathrm{Ni}$. The results obtained were as follows:

(1) Microstructure of lath martensite is markedly refined by lowering the solution treatment temperature, nevertheless no large difference is found on the nominal stressstrain curves, especially on the yielding behavior.

(2) Low elastic limit of ultra low carbon martensite is due to the existence of high density of mobile dislocation 
which has been introduced during martensitic transformation. Extra mobile dislocations can be eliminated by charging small amount of pre-strain more than $0.6 \%$ and this leads to an increase of $0.2 \%$ proof stress.

(3) $0.2 \%$ proof stress of the specimens with $5 \%$ cold rolling is just on the extended line of the Bailey-Hirsch relation which has been established for cold rolled iron. This suggests that substantial yield strength of carbon free martensite is determined by only the mechanism of dislocation strengthening without the contribution by grain refinement strengthening depending on microstructural parameters such as prior austenite grain size, packet size and block size.

(4) Solid solution strengthening by Ni does not appear in martensitic steels which contains high density of dislocation, even though it is significant in ferritic steels.

\section{REFERENCES}

1) R. A. Grange, C. R. Hribal and L. F. Porter: Metall. Trans. A, 8A (1977), 1775 .

2) J. I. Burns, T. L. Moore and R. S. Archer: Trans. ASM, 26 (1938), 1.

3) G. Krauss: Hardenability concepts with applications to steel, ed. by
D. V. Doane and J. S. Kirkaldy, Met. Soc. AIME, Warrendale, PA, USA, (1978), 229

4) G. R. Speich and H. Warlimont: J. Iron Steel Inst., 206 (1968), 385.

5) J. M. Chilton and P. M. Kelly: Acta Metall., 16 (1968), 637.

6) Y. Maki, K. Tsuzaki and I. Tamura: Trans. Iron Steel Inst. Jpn., 20 (1980), 207.

7) T. Swarr and G. Krauss: Metall. Trans. A, 7A (1976), 41.

8) S. Morito, H. Yoshida, T. Maki and X. Huang: Mater. Sci. Eng. A, 438-440 (2006), 237.

9) M. Kehoe and P. M. Kelly: Scr. Metall., 4 (1970), 473.

10) F. B. Pickering: Hardenability concepts with applications to steel, ed. by D. V. Doane and J. S. Kirkaldy, Met. Soc. AIME, Warrendale, PA, USA, (1978), 179.

11) K. Nakashima, Y. Fujimura, H. Matsubayashi, T. Tsuchiyama and S. Takaki: Tetsu-to-Hagané, 93 (2007), 459.

12) K. Takano, M. Sakakibara, T. Matsui and S. Takaki: Tetsu-toHagané, 86 (2000), 123.

13) G. K. Williamson and R. E. Smallman: Philos. Mag., 8 (1956), 34.

14) G. R. Speich and P. R. Swann: J. Iron Steel Inst., 203 (1965), 480.

15) W. P. Rees, B. E. Hopkins and H. R. Tipler: J. Iron Steel Inst., 177 (1954), 93.

16) H. H. Kranzlein, M. S. Burton and G. V. Smith: Trans. AIME, 233 (1965), 64.

17) M. J. Roberts and W. S. Owen: Trans. ASM, 60 (1967), 687.

18) J. Syarif, K. Nakashima, T. Tsuchiyama and S. Takaki: ISIJ Int., 47 (2007), 340

19) Y. Nishizawa: Bull. Jpn. Inst. Met., 12 (1973), 189.

20) Y. Nishizawa: Bull. Jpn. Inst. Met., 12 (1973), 321. 